\title{
Do Rerevision Rates Differ After First-time Revision of Primary THA With a Cemented and Cementless Femoral Component?
}

\author{
Kirill Gromov MD, PhD, Alma B. Pedersen MD, PhD, \\ Søren Overgaard MD, PhD, DMSc, Peter Gebuhr MD, \\ Henrik Malchau MD, PhD, Anders Troelsen MD, PhD, DMSc
}

Published online: 12 March 2015

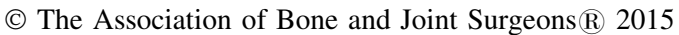

\begin{abstract}
Background Worldwide use of cementless fixation for total hip arthroplasty (THA) is on the rise despite some evidence from the world's registries suggesting inferior survivorship compared with cemented techniques. The patterns of bone loss associated with failed cementless and cemented THAs may prejudice the results of future revision procedures; however, this has not been documented. Questions/purposes The purpose of this study was to compare (1) the risk for rerevision of first revision THA; (2) the patterns of femoral bone loss at the time of first
\end{abstract}

Each author certifies that he or she, or a member of his or her immediate family, has no funding or commercial associations (eg, consultancies, stock ownership, equity interest, patent/licensing arrangements, etc) that might pose a conflict of interest in connection with the submitted article.

All ICMJE Conflict of Interest Forms for authors and Clinical Orthopaedics and Related Research ${ }^{\mathbb{R}}$ editors and board members are on file with the publication and can be viewed on request.

Each author certifies that his or her institution approved the human protocol for this investigation, that all investigations were conducted in conformity with ethical principles of research, and that informed consent for participation in the study was obtained.

This work was performed at the Department of Orthopedics, Copenhagen University Hospital Hvidovre, Copenhagen, Denmark.

K. Gromov, P. Gebuhr, A. Troelsen

Department of Orthopedic Surgery, Copenhagen University

Hospital Hvidovre, Copenhagen, Denmark

\section{A. B. Pedersen}

Department of Clinical Epidemiology, Aarhus University

Hospital, Aarhus, Denmark

S. Overgaard

Department of Orthopaedic Surgery, Traumatology and Clinical Institute, Odense University Hospital, Odense, Denmark revision of primary THA; (3) the reasons for first revision of primary THA; and (4) the time to first revision of primary THA between primary cementless and cemented femoral components.

Methods Primary THAs with cemented $(\mathrm{n}=1791)$ and uncemented $(\mathrm{n}=805)$ femoral components that subsequently sustained first revision of the femoral component were identified from the Danish Hip Arthroplasty Registry (DHR). As of 2012, 120,988 primary THAs and 19,282 revisions were registered in the DHR with completeness of 97\% and $90 \%$ for primary and revision THA, respectively. Median followup for revisions of primary THA with cemented and cementless femoral component was 4 years (range, 0-17 years) and 2 years (range, 0-16 years), respectively. Survival of first revision THA, with second revision of the femur as outcome, was evaluated using hazard ratios (HRs) with 95\% confidence interval (CI) adjusting for potential confounding. All patient- and surgery-related data are collected from Danish medical databases. Recording of bone defects in the DHR is based on surgeons' intraoperative findings.

Results With the numbers studied, we found no differences in the risk of second revision between the overall cohort between cementless and cemented techniques (HR, 1.32; 95\% CI, $0.97-1.80 ; \mathrm{p}=0.076$ ); however, a second revision for

H. Malchau

Orthopaedic Department, Massachusetts General Hospital/ Harvard Medical School, Boston, MA, USA

K. Gromov $(\bowtie)$

Department of Orthopedics, Copenhagen University Hospital Hvidovre, Kattegaard Allé 30, 2650 Copenhagen, Denmark e-mail: kirgromov@gmail.com 
any reason was more likely in patients $<70$ years old in whom the index arthroplasty was performed using a cementless technique (HR, 1.48; 95\% CI, 1.01-2.17; $\mathrm{p}=0.046)$. Increasingly severe femoral bone defects of type II (30\% [532 of 1791] versus 13\% [104 of 805]; p < 0.001) type III (11\% [200 of 1791] versus 2\% [12 of 805]; $\mathrm{p}<0.001)$ and type IV (1\% [26 of 1791 ] versus $0.4 \%$ [three of 805]; $\mathrm{p}=0.016$ ) were more frequent at revisions of cemented femoral components compared with cementless femoral components. Indications for first revision differed between primary cemented and uncemented femoral components, because a larger proportion of cemented femoral components was revised as a result of aseptic loosening compared with cementless femoral components (74\% [1329 of 1791] versus $25 \%$ [197 of 805]; $\mathrm{p}<0.001$ ), whereas a larger proportion of cementless femoral components was revised as a result of a fracture compared with cemented femoral components (46\% [371 of 805] versus 10\% [168 of 1791 ]; $\mathrm{p}<0.001)$. Failure before 5 years was more likely in cementless femoral components than cemented femoral components (91\% [733 of 805] versus 44\% [749 of 1791], $\mathrm{p}<0.001)$.

Conclusions We found no differences in the risk of second revision in the overall cohort between cementless and cemented techniques; however, we observed an increased risk for rerevision THA performed on patients $<70$ years whose index THAs were performed using cementless components when looking at all causes for revision, even after adjusting for the most likely confounding factors. Our data suggest that increased use of cementless fixation in primary THA may lead to inferior survivorship of first revision THA.

Level of Evidence Level III, therapeutic study.

\section{Introduction}

Although the optimal component fixation method in primary THA is still debated, several studies have shown increased use of the cementless technique in most parts of the world [14, 19, 27]. The potential for biological fixation as well as extensive marketing and excellent outcomes in single-center studies of cementless femoral components may account for the increasing worldwide use of cementless fixation [16]. Such increased use of cementless components might be considered paradoxical because some registry data suggest inferior survival of cementless THA [7, 19, 21, 27].

Changes in femoral fixation technique, from cemented to cementless, can lead to changes in reoperation patterns, including the indications for and durability of subsequent revisions, as well as an effect on femoral bone defects at the time of revision, which might influence the risk profile of those revisions $[1,12,17]$. However, to our knowledge, the degree to which any of this might be the case has not been evaluated.

In this registry and population-based study, we wanted to investigate the role that primary femoral fixation plays in survival of first revision arthroplasty by (1) comparing the risk for rerevision of first revision THA performed on primary cementless and cemented femoral components; (2) investigating femoral bone defects at the time of first revision of primary THA performed with cementless and cemented femoral components; (3) comparing indications for first revision of primary THA performed with cementless and cemented femoral components; and (4) investigating time to first revision of primary THA performed with cementless and cemented femoral components.

\section{Patients and Methods}

The Danish Hip Arthroplasty Registry (DHR) was established in 1995 and contains detailed clinical data on primary THA as well as revision. Revision is defined as exchange of a part or the whole prosthesis or removal of the prosthesis. For this study only revisions with exchange of a part or the whole prosthesis were included. All active hospitals, private as well as public, report to DHR. As of 2012, 120,988 primary THAs and 19,282 revisions were registered in DHR with completeness of $97 \%$ and $90 \%$ for primary and revision THA, respectively [23].

The Danish National Registry of Patients was established in 1977 and holds information on all admissions and discharges and up to 20 diagnoses for every discharge from public somatic hospitals in Denmark [2]. Diagnoses are classified according to the Danish version of the International Classification of Diseases (ICD). The eighth edition (ICD-8) was used from 1977 to 1993 and the tenth edition (ICD-10) has been used hereafter. The physician discharging the patient assigns all discharge diagnoses [3].

The Civil Registration System holds information on vital status of all Danish citizens including changes in address, date of emigration, and date of death, because all Danish citizens are assigned at birth a unique 10-digit personal number (CPR) encoding age, gender, and date of birth since 1968 [11]. Use of the CPR number enables unambiguous linkage among all Danish administrative registries and allows tracking of patients who died, emigrated, were treated in another department, or were admitted to another hospital than during primary treatment.

According to the aim of the study, only primary THAs with a cementless femoral component and primary THAs with a cemented femoral component that subsequently sustained first-time revision of the femoral component for 
Table 1. Patient demographics at the time of primary THA

\begin{tabular}{lcc}
\hline Demographic & $\begin{array}{l}\text { Primary THA with cemented femoral } \\
\text { component }\end{array}$ & $\begin{array}{c}\text { Primary THA with cementless femoral } \\
\text { component }\end{array}$ \\
\hline Gender, number (\%) & $943(53 \%)$ & $375(47 \%)$ \\
Male & $848(47 \%)$ & $430(53 \%)$ \\
Female & $65(58-72)$ & $66(59-72)$ \\
Age (median years; IQR) Primary & & \\
$\quad$ surgery & $1447(81 \%)$ & $597(74 \%)$ \\
Diagnosis, number (\%) & $344(19 \%)$ & $208(26)$ \\
Primary OA & 1791 & 805 \\
Other* & & 0.200 \\
Total number & & $<0.001$ \\
\hline
\end{tabular}

* Other includes: dysplasia, acetabular fracture, acute femoral fracture, complication after femoral fracture, ankylosing spondylitis, Legg-CalvéPerthes disease, rheumatoid arthritis, other arthritis, necrosis of the femoral head, epiphysiolysis, congenital dislocation of the hip, traumatic dislocation of the hip, and other; IQR = interquartile range; $\mathrm{OA}=$ osteoarthritis.

any reason were included in the study population $(\mathrm{n}=2596)$. In patients who underwent bilateral THAs (simultaneous or staged) during the surveillance procedure, we only considered the first primary THA for our analysis, and we followed that arthroplasty to the point of revision. Resurfacing arthroplasties were excluded. From the DHR we identified 805 primary THAs with cementless femoral components and 1791 primary THA with cemented femoral components that sustained a first revision as a result of any reason. All primary THAs were performed between January 1, 1995, and December 31, 2012.

More male patients received a cementless femoral component compared with female patients at the time of primary THA (Table 1). Patients with cementless femoral components were younger at the time of first revision compared with patients with cemented femoral components when looking for all causes for revision (Table 2).

Charlson Comorbidity Index at the time of primary THA and first revision was collected from the Danish National Registry of Patients [6]. We classified the patients undergoing THA into three groups according to degree of comorbidity: patients undergoing THA with an index score of 0 (low), which corresponds to patients with no previously recorded disease categories implemented in the Charlson Comorbidity Index; patients undergoing THA with a Charlson Comorbidity Index score of 1 to 2 (medium); and patients undergoing THA with a Charlson index score of 3 or more (high) at the time of surgery.

Femoral bone defects according to Saleh et al. [26] (Table 3) and bone transplantation of femur at the time of first revision were recorded from the DHR. Registrations of bone defects in the DHR are based on surgeons' intraoperative findings and were first introduced in DHR in 2000.

The primary outcome was risk for rerevision of first revision THA performed on primary cementless and cemented femoral components and femoral bone defects at the time of first revision, indications for first revision, and time to first revision of primary THA performed with cementless and cemented femoral components were secondary outcomes.

Followup started at the day of the first revision of the primary THA and ended on the day of the second revision, death, or December 31, 2012, whichever came first. Median followup for revisions of primary THA with cemented femoral component was 4 years (range, 0-17 years), whereas median followup for revisions of primary THA with a cementless femoral component was 2 years (range, 0-16 years).

Kaplan-Meier survival analysis was used to estimate cumulative incidence of the second revision of femoral component as a result of any reason after the first revision of the femur component attributable to any reason.

Cox regression analyses were used to calculate crude hazard ratio (HR) for primary THA with cementless femoral component that sustained a first revision as a result of any reason compared with primary THA with a cemented femoral component that sustained a first revision as a result of any reason for all patients and separately for patients $<70$ years as well as $\geq 70$ years of age.

HR was adjusted for gender, age $(<70$ years $/ \geq 70$ years) at the time of first revision, fixation type of the first revision (cemented, hybrid, cementless), Charlson Comorbidity Index at the time of the first revision (low, medium, high), simultaneous acetabular revision (yes/no), reason for the first revision, time until the first revision ( $<1$ year, 1-5 years, $>5$ years), and hospital volume ( $\leq 3$ revisions/year, 3-6 revisions/year, $\geq 6$ revisions/ year). The assumption of the Cox proportional hazard model was assessed graphically with use of log-log plots and Schoenfeld residuals and was found suitable.

In addition, we calculated HR for primary THA with a cementless femur component that sustained a first revision 
Table 2. Patient demographics at the time of first revision and indications for first revision of primary cemented and cementless femoral components as registered in the Danish Hip Arthroplasty Registry

\begin{tabular}{|c|c|c|c|c|}
\hline Registered parameter & Value & $\begin{array}{l}\text { Primary THA with a cemented } \\
\text { femoral component }\end{array}$ & $\begin{array}{l}\text { Primary THA with a cementless } \\
\text { femoral component }\end{array}$ & $\mathrm{p}$ values \\
\hline Age (median years; IQR) & & $74(67-79)$ & $67(60-74)$ & $<0.001$ \\
\hline \multirow{9}{*}{$\begin{array}{l}\text { Indication for revision, } \\
\text { number }(\%)\end{array}$} & Aseptic loosening & $1329(74 \%)$ & $197(25 \%)$ & $<0.001$ \\
\hline & $\begin{array}{l}\text { Osteolysis/granuloma } \\
\text { without loosening }\end{array}$ & $11(0.6 \%)$ & $4(0.5 \%)$ & 0.715 \\
\hline & Infection & $93(5 \%)$ & $51(6 \%)$ & 0.239 \\
\hline & Femur fracture & $168(9 \%)$ & $371(46 \%)$ & $<0.001$ \\
\hline & Dislocation & $129(7 \%)$ & $73(9 \%)$ & 0.107 \\
\hline & Components failure & $30(2 \%)$ & $24(3 \%)$ & 0.031 \\
\hline & Pain & $12(0.7 \%)$ & $53(7 \%)$ & $<0.001$ \\
\hline & $\begin{array}{l}\text { Polyethylene wear without } \\
\text { loosening }\end{array}$ & $3(0.2 \%)$ & - & - \\
\hline & Other & $15(0.8 \%)$ & $32(4 \%)$ & $<0.001$ \\
\hline \multirow[t]{3}{*}{ Revision type, number (\%) } & Uncemented & $1063(59 \%)$ & $673(84 \%)$ & $<0.001$ \\
\hline & Hybrid A + B* & $564(31 \%)$ & $118(15 \%)$ & $<0.001$ \\
\hline & Cemented & $164(9 \%)$ & $14(2 \%)$ & $<0.001$ \\
\hline \multirow[t]{3}{*}{ Acetabular exchange } & Yes & $468(26 \%)$ & $55(7 \%)$ & $<0.001$ \\
\hline & No & $436(24 \%)$ & $141(18 \%)$ & $<0.001$ \\
\hline & Unknown & $887(50 \%)$ & $609(75 \%)$ & $<0.001$ \\
\hline \multirow[t]{3}{*}{ Time until revision } & $<1$ year & $200(11 \%)$ & $538(67 \%)$ & $<0.001$ \\
\hline & $1-5$ years & $549(31 \%)$ & $195(24 \%)$ & $<0.001$ \\
\hline & $>5$ years & $1042(58 \%)$ & $72(9 \%)$ & $<0.001$ \\
\hline \multirow[t]{3}{*}{ Hospital volume ${ }^{\dagger}$} & $\leq 3$ & $192(11 \%)$ & $65(8 \%)$ & 0.037 \\
\hline & $3-6$ & $845(47 \%)$ & $340(42 \%)$ & $<0.001$ \\
\hline & $\geq 6$ & $754(42 \%)$ & $400(50 \%)$ & $<0.001$ \\
\hline Total number & & 1791 & 805 & \\
\hline
\end{tabular}

* Hybrid A = cementless femur, cemented acetabulum, Hybrid B = cemented femur, cementless acetabulum; 'hospital volume: number of revision procedures performed per year; IQR $=$ interquartile range.

as a result of aseptic loosening compared with primary THA with a cemented femur component that sustained a first revision resulting from aseptic loosening for all patients and separately for patients $<70$ years as well as $\geq 70$ years of age. The Wilcoxon Mann-Whitney test was used to compare continuous nonparametric variables and the chi square test to compare parametric categorical variables. Probability values $<0.05$ were considered significant.

The study was approved by the Danish Data Committee: approval number 2007-58-0015.

\section{Results}

With the numbers studied, we found no differences in the risk of second revision between the overall cohort between cementless and cemented techniques (hazard ratio [HR], 1.32; 95\% confidence interval [CI], 0.97-1.80; $\mathrm{p}=0.076$ ) (Fig. 1); however, a second revision for any reason was more likely in patients $<70$ years old in whom the index arthroplasty was performed using a cementless technique (HR, 1.48; 95\% CI, 1.01-2.17; $\mathrm{p}=0.046$ ) (Fig. 2). When the first revision was performed because of aseptic loosening, there was no difference between rerevision rates of primary cementless femoral components compared with cemented femoral components (HR, 1.06; 95\% CI, 0.66$1.72 ; \mathrm{p}=0.802)$ (Table 4).

Increasingly severe femoral bone defects were more frequent at revisions of cemented femoral components compared with cementless femoral components ( $p<0.001$ for all comparisons; Table 4). When looking only at THA revised as a result of aseptic loosening, we found the same pattern with a higher proportion of cementless femoral components having Type I defects compared with cemented femoral components (68\% [134 of 197] versus $34 \%$ [452 of 1329]; $\mathrm{p}<0.001)$, whereas cemented femoral components had more Type II (45\% [89 of 197] versus $27 \%$ [359 of 1329]; $p<0.001)$, Type III (17\% [33 of 197] versus $2 \%$ [27 of 1329]; $\mathrm{p}<0.001)$, Type IV ( $2 \%$ [four of 
197] versus $0 \%$ [zero of 1329]; $\mathrm{p}<0.001$ ), and Type $\mathrm{V}$ (1\% [two of 197] versus $0.6 \%$ [eight of 1329]; $p=0.028$ ) defects compared with cementless femoral components. Type VI defects were more common in revisions of cementless femoral components ( $2 \%$ [four of 197] versus $1 \%$ [eight of 1329]; $\mathrm{p}<0.019$ ). Bone transplantation was more frequently used in revisions of cemented femoral components compared with cementless femoral components $(25 \%$ [448 of 1791] versus 8\% [64 of 805]; $\mathrm{p}<0.001$ ).

Indications for first revision differed between primary cemented and uncemented femoral components. A larger proportion of cemented femoral components were revised as a result of aseptic loosening compared with cementless femoral components (74\% [1329 of 1791] versus 25\% [197 of 805]; $\mathrm{p}<0.001$ ), whereas a larger proportion of cementless femoral components was revised as a result of a fracture compared with cemented femoral components (46\% [371 of 805] versus $10 \%$ [168 of 1791]; $\mathrm{p}<0.001$ ) (Table 2).

Table 3. Femoral bone defects classified according to Saleh et al. [26]

\begin{tabular}{lllr}
\hline $\begin{array}{l}\text { Femoral } \\
\text { bone } \\
\text { defect type }\end{array}$ & $\begin{array}{l}\text { Primary THA with } \\
\text { a cemented femoral } \\
\text { component }\end{array}$ & $\begin{array}{l}\text { Primary THA with } \\
\text { a cementless femoral } \\
\text { component }\end{array}$ & p values \\
\hline Unclassified & $478(27 \%)$ & $103(13 \%)$ & $<0.001$ \\
Type I & $498(28 \%)$ & $496(62 \%)$ & $<0.001$ \\
Type II & $532(30 \%)$ & $104(13 \%)$ & $<0.001$ \\
Type III & $200(11 \%)$ & $12(2 \%)$ & $<0.001$ \\
Type IV & $26(1 \%)$ & $3(0.4 \%)$ & 0.016 \\
Type V & $21(1 \%)$ & $11(1 \%)$ & 0.669 \\
Type VI & $36(2 \%)$ & $76(9 \%)$ & $<0.001$ \\
\hline
\end{tabular}

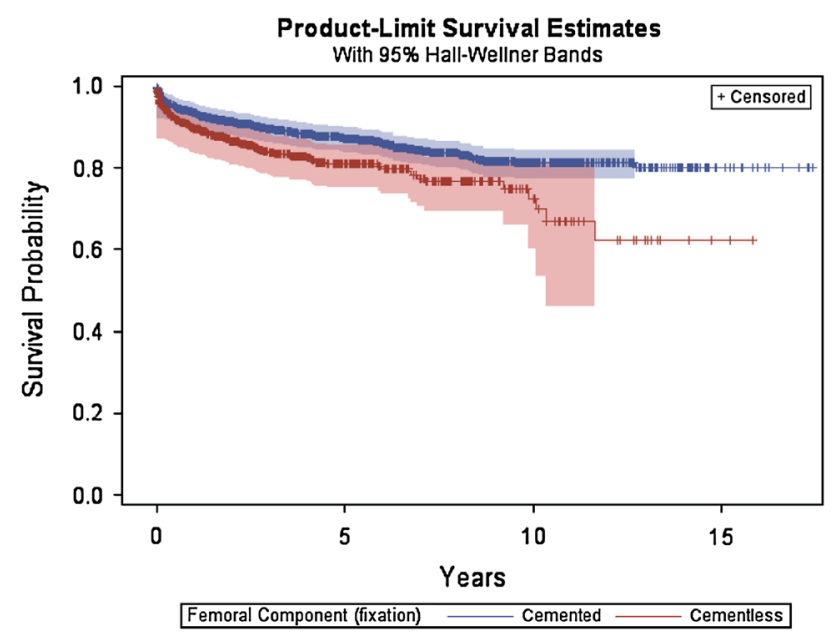

Fig. 1 Kaplan-Meier survival analysis was used to estimate cumulative incidence of the second revision of femoral component in all patients after the first revision of the femur component attributable to any reason.
Primary cementless femoral components are more frequently rerevised as a result of infection compared with primary cementless femoral components (32\% [40 of 162] versus $21 \%$ [48 of 227] $(\mathrm{p}=0.027)$ (Table 5). Failure before 5 years was more likely in the cementless THAs than the cemented THAs (91\% [733 of 805] versus 44\% [749 of 1791]; $\mathrm{p}<0.001$ ) (Table 3) when looking at all reasons for revision. The same pattern was found when only looking at femoral components revised for aseptic loosening, because $37 \%$ (73 of 197) of cementless femoral components were revised within 1 year compared with only $4 \%$ (47 of 1329) of cemented femoral components $(\mathrm{p}<0.001)$. Sixty-five percent (871 of 1329) of cemented femoral components were revised as a result of aseptic loosening later than 5 years after the index surgery compared with $16 \%$ (31 of $197)$ of cementless femoral components $(p<0.001)$.

\section{Discussion}

Worldwide use of cementless fixation for THA is on the rise despite some evidence from the world's registries suggesting inferior survivorship compared with cemented techniques. The patterns of bone loss associated with failed cementless and cemented THAs may prejudice the results of future revision procedures; however, this has not been documented. In this registry-based study, we found an increased risk of second revision after first-time revision performed on patients $<70$ years old whose index THA was performed using a cementless technique. We also found a trend toward increased risk of second revision after first-time revision performed on any patients whose index THA was performed using a cementless technique.

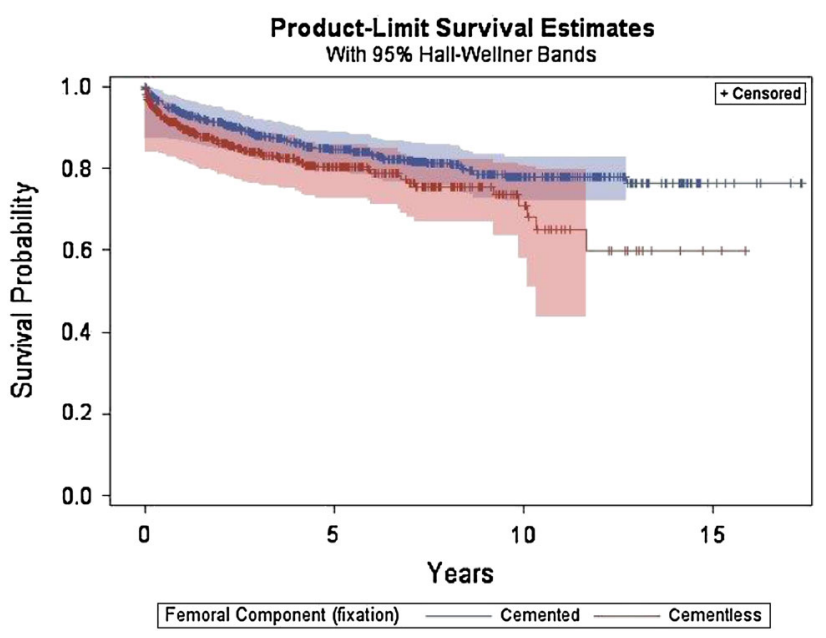

Fig. 2 Kaplan-Meier survival analysis was used to estimate cumulative incidence of the second revision of femoral component in patients $<70$ years old after the first revision of the femur component attributable to any reason. 
Table 4. Crude and adjusted HR for survival of revision THA performed on patients with primary THA with cementless femoral components compared with primary THA with cemented femoral components

\begin{tabular}{|c|c|c|c|c|c|}
\hline Patients (number) & $\begin{array}{l}\text { Rerevised primary THA with } \\
\text { cementless femoral component, } \\
\text { number/Number }(\%)\end{array}$ & $\begin{array}{l}\text { Rerevised primary THA with } \\
\text { cemented femoral component, } \\
\text { number/Number }(\%)\end{array}$ & $\begin{array}{l}\text { Crude HR } \\
(95 \% \mathrm{CI})\end{array}$ & $\begin{array}{l}\text { Adjusted* HR } \\
(95 \% \mathrm{CI})\end{array}$ & $\mathrm{p}$ value \\
\hline $\begin{array}{l}\text { All (2694), } \\
\text { all reasons for revision }\end{array}$ & $127 / 805(16 \%)$ & $227 / 1791(13 \%)$ & $1.57(1.26-1.95)$ & $1.32(0.97-1.80)$ & 0.076 \\
\hline $\begin{array}{l}<70 \text { years }(1248), \\
\text { all reasons for revision }\end{array}$ & $89 / 504(18 \%)$ & $108 / 649(16 \%)$ & $1.45(1.09-1.92)$ & $1.48(1.01-2.17)$ & 0.046 \\
\hline $\begin{array}{l}\geq 70 \text { years }(1446), \\
\text { all reasons for revision }\end{array}$ & $38 / 301(13 \%)$ & $119 / 1142(10 \%)$ & $1.55(1.07-2.24)$ & $1.10(0.65-1.85)$ & 0.732 \\
\hline $\begin{array}{l}\text { Revised as a result of } \\
\text { aseptic loosening (1550) }\end{array}$ & 29/197 (15\%) & $166 / 1329(12 \%)$ & $1.48(1.00-2.20)$ & $1.06(0.66-1.72)$ & 0.802 \\
\hline $\begin{array}{l}\text { Revised as a result of all } \\
\text { reasons except aseptic } \\
\text { loosening (1550) }\end{array}$ & 98/608 (16\%) & $61 / 462(13 \%)$ & $1.44(1.04-1.99)$ & $1.33(0.89-2.00)$ & 0.163 \\
\hline
\end{tabular}

* Adjusted for: age at first revision $(<70, \geq 70$ years), gender (male, female), fixation type of first revision (cemented, hybrid, cementless), Charlson Comorbidity Index (low, medium, high), acetabular revision (yes, no), reason for revision, hospital volume (revisions per year: $<3,3-$ $6,>6$ ), and time until first revision $(<1$ year, $1-5$ years, $\geq 5$ years); HR $=$ hazard ratio; $\mathrm{CI}=$ confidence interval.

Table 5. Indication for second revision of primary cemented and cementless femoral components as registered in the Danish Hip Arthroplasty Registry

\begin{tabular}{llll}
\hline $\begin{array}{l}\text { Registered } \\
\text { parameter }\end{array}$ & $\begin{array}{l}\text { Primary THA with a } \\
\text { cemented femoral } \\
\text { component }\end{array}$ & $\begin{array}{l}\text { Primary THA with a p values } \\
\text { cementless femoral } \\
\text { component }\end{array}$ & \\
\hline $\begin{array}{c}\text { Aseptic } \\
\text { loosening }\end{array}$ & $80(35 \%)$ & $36(29 \%)$ & 0.201 \\
$\begin{array}{l}\text { Infection } \\
\text { Femur fracture }\end{array}$ & $48(21 \%)$ & $40(32 \%)$ & 0.027 \\
$\begin{array}{l}\text { Dislocation } \\
\text { Component } \\
\text { failure }\end{array}$ & $54(24 \%)$ & $10(8 \%)$ & 0.887 \\
Pain & $7(3 \%)$ & $24(19 \%)$ & 0.304 \\
Other & $7(3 \%)$ & $7(6 \%)$ & 0.915 \\
\hline
\end{tabular}

Our study has several limitations, most of which are linked to the registry-based observational design. We were able to adjust for a number of confounders; however, other potential confounders not identified by this study such as articulation, surgical skill, revision implant type, and revision technique might affect the risk for rerevision. Head size and articulation could be potential confounders in our study. However, we believe that confounding from these factors is limited because head size and articulation mostly affect the acetabular side. This is supported by findings presented by Pedersen et al. [24], who did not find adjustment for femoral head size and bearing surfaces to influence risk estimates when comparing fixation technique in relation to different revision outcomes. Further on, registry data on bone defects are not validated and might be associated with large variation between observers. It is also important to notice the high percentage of unclassified bone defects, particularly in the cemented group, which potentially could result in bias. Also, revision is not the only relevant outcome after revision surgery because we did not investigate mortality or patient-reported outcomes in our cohorts. Finally, Kaplan-Meier estimate in the presence of competing risk can be biased and it can be argued that cumulative incidence is a more appropriate method to calculate revision risk. However, we decided to extend Kaplan-Meier estimates presenting the number and mortality risk in the comparison groups during the followup period as suggested by recent statistical guidelines for register-based studies [25].

We found an increased risk of rerevision, when adjusted for potential confounders, for first revisions on primary THA with a cementless femoral component compared with first revisions of primary THA with a cemented femoral component among all patients, in particular in younger patients ( $<70$ years). To our knowledge, this is the first evidence that fixation method of the femoral component in primary THA plays a role in survival of revision THA. This finding, of superior survival of first revisions of primary THA with a cemented femoral component, is somewhat surprising because we also found severe bone defects more frequently reported intraoperatively during first revision of cemented femoral components compared with first revision of cementless femoral components and severe bone defects have been linked to inferior survival of revision THA by several authors [12, 17, 28]. Despite adjustment for potential confounders, which included indication for first 
revision, we believe that different indications for revision can potentially explain this finding. We did not find an increased risk for revision for primary THA with cementless femoral components when only looking at THAs revised as a result of aseptic loosening, suggesting that technical and mechanical problems of uncemented fixations play an important role in survival of revision THA. Residual confounding is possible, because we do not include revision technique (such as impaction grafting) and specific type of revision prosthesis in our analysis. Also, because cementless fixation was less common early in the observation period, and revision surgery results may have improved over time owing to improvement of surgical techniques and implants, the apparent benefit of cemented primary fixation may be underestimated. Furthermore, surgeons' reluctance to revise cemented femoral components might also act as a confounder.

We found a higher proportion of severe bone defects as well as a need for bone grafting reported at first revision of cemented femoral components compared with cementless femoral components. This difference could be attributed to the indication for revision and the biology leading to loosening, because THAs revised for aseptic loosening are bound to have more osteolysis compared with THAs revised because of fracture. However, we found the same difference in bone defects when only looking at THAs revised because of aseptic loosening. This can either be the result of different pathology of osteolysis around cemented femoral stems $[8,15,20,22,29]$ or the result of delayed revision of cemented implants, as suggested by the older age of patients in this group. A potential confounder to this finding is change in type of polyethylene used for primary THA. The Swedish hip registry shows increased use of highly crosslinked polyethylene (HXLPE) over time, from only a few percent in 2004 to approximately $50 \%$ of all primary THAs in 2010 [13]. Simultaneously more primary THAs were being performed using the cementless technique; Troelsen et al. [27] showed cementless fixation use in Denmark to increase from $47 \%$ to $68 \%$ between 2006 and 2010. Because HXLPE has reduced wear compared with traditional polyethylene [5], it is plausible that increased use of HXLPE reduced bone defects in THA revised for aseptic loosening over time, thus being a potential confounder to our findings of less bone loss in revised cementless THAs. This, however, is speculative. Finally, the higher patient age in the cemented group could contribute to these findings, because older patients tend to have lower bone mineral density and therefore are more likely to have more extensive bone loss. This is supported by findings by Dan et al. [8], who found osteoporosis to be more frequent in patients with cemented femoral prosthesis in comparison with those with cementless ones as well as findings by Foran et al., who showed cemented stems have an increased risk for proximal femoral remodeling [10]. Classification of femoral bone loss around periprosthetic fracture can explain that Type VI defects were more frequent in revisions of cementless femoral components compared with cemented femoral components. The larger proportion of missing registration of bone defects for revisions performed on cemented femoral stems can be explained by late introduction of bone defect classification (in 2000) in DHR. Because more cemented femoral components were used before 2000 , more defects in cemented femoral components would be unclassified.

We found femoral fracture and aseptic loosening to be the most common indications for revision of cementless and cemented femoral components, respectively. A high prevalence of revision resulting from femoral fracture of cementless femoral components is in accordance with previous studies that have highlighted the increased risk of femoral fracture while using cementless stems $[4,9,14$, 18].

When looking at age and timing of revision THAs, we found that patients with cemented femoral components were older and were more frequently revised later than 5 years after the index surgery compared with patients whose index THAs were performed with cementless femoral components. This finding may be explained by different loosening patterns for the two groups, because femoral fracture was the most frequent revision indication for cementless femoral components, whereas aseptic loosening was the most frequent indication for revision for cemented femoral components. Femoral fractures are much more likely to occur early in the followup period [9, 14], whereas aseptic loosening is rarely seen before 5 to 10 years postoperatively, which might lead to cementless femoral components being revised earlier compared with cemented femoral components. However, this can only partially explain the age difference and difference in time until revision in the two groups, because we found a similar age difference and difference in time until first revision when only looking at THAs revised as a result of aseptic loosening. This age difference and difference in time until first revision support the hypothesis that surgeons are more hesitant in revising primary THA with cemented femoral components as a result of perceived increased technical difficulty of the revision surgery. This is in accordance with our finding that more severe types of bone defects are found during revisions of cemented femoral components as well as more of these revisions needing bone grafting.

In this registry- and population-based study, we found no differences in the risk of second revision in the overall cohort between cementless and cemented techniques; however, we observed an increased risk for rerevision THA performed on patients $<70$ years, whose index THAs 
were performed using cementless components when looking at all causes for revision, even after adjusting for the most likely confounding factors. Adjusted risk for rerevision was not different for revisions on cemented and cementless primary THA when only looking at revisions resulting from aseptic loosening. A larger proportion of primary cementless femoral components is revised as a result of fracture, whereas a larger proportion of primary cemented femoral components is revised because of aseptic loosening. Different indications for first revision could potentially explain inferior survival of revision performed on cementless THA.

\section{References}

1. Abdulkarim A, Ellanti P, Motterlini N, Fahey T, O’Byrne JM. Cemented versus uncemented fixation in total hip replacement: a systematic review and meta-analysis of randomized controlled trials. Orthop Rev (Pavia). 2013;5:e8.

2. Andersen TF, Madsen M, Jørgensen J, Mellemkjoer L, Olsen JH. The Danish National Hospital Register. A valuable source of data for modern health sciences. Dan Med Bull. 1999;46:263-268.

3. Anonymous. International Classification of Diseases (ICD). Geneva, Switzerland: World Health Organization; 2008.

4. Berry DJ. Epidemiology: hip and knee. Orthop Clin North Am. 1999;30:183-190.

5. Bragdon CR, Doerner M, Martell J, Jarrett B, Palm H, Malchau H. The 2012 John Charnley Award: Clinical multicenter studies of the wear performance of highly crosslinked remelted polyethylene in THA. Clin Orthop Relat Res. 2013;471:393-402.

6. Charlson ME, Pompei P, Ales KL, MacKenzie CR. A new method of classifying prognostic comorbidity in longitudinal studies: development and validation. J Chronic Dis. 1987;40:373-383.

7. Corbett KL, Losina E, Nti AA, Prokopetz JJZ, Katz JN. Population-based rates of revision of primary total hip arthroplasty: a systematic review. PLoS One. 2010;5:e13520.

8. Dan D, Germann D, Burki H, Hausner P, Kappeler U, Meyer RP, Klaghofer R, Stoll T. Bone loss after total hip arthroplasty. Rheumatol Int. 2006;26:792-798.

9. Fernandez-Fernandez R, García-Elias E, Gil-Garay E. Peroperative fractures in uncemented total hip arthroplasty: results with a single design of stem implant. Int Orthop. 2008;32:307-313.

10. Foran JRH, Brown NM, Della Valle CJ, Levine BR, Sporer SM, Paprosky WG. Prevalence, risk factors, and management of proximal femoral remodeling in revision hip arthroplasty. $J$ Arthroplasty. 2013;28:877-881.

11. Frank L. Epidemiology. When an entire country is a cohort. Science. 2000;287:2398-2399.

12. Garcia-Cimbrelo E, Garcia-Rey E, Cruz-Pardos A. The extent of the bone defect affects the outcome of femoral reconstruction in revision surgery with impacted bone grafting: a five- to 17-year follow-up study. J Bone Joint Surg Br. 2011;93:1457-1464.

13. Garellick G, Rogmark C, Karrholm J, Rolfson O. Swedish Hip Arthroplasty Registry Annual Report 2012. Available at: www.shpr.se/ en/Publications/DocumentsReports.aspx . Accessed September 2014.
14. Hailer NP, Garellick G, Kärrholm J. Uncemented and cemented primary total hip arthroplasty in the Swedish Hip Arthroplasty Register. Acta Orthop. 2010;81:34-41.

15. Jones LC, Hungerford DS. Cement disease. Clin Orthop Relat Res. 1987;225:192-206.

16. Khanuja HS, Vakil JJ, Goddard MS, Mont MA. Cementless femoral fixation in total hip arthroplasty. J Bone Joint Surg Am. 2011;93:500-509.

17. Lachiewicz PF, Soileau ES. What is the survivorship of fully coated femoral components in revision hip arthroplasty? Clin Orthop Relat Res. 2015;473:549-554.

18. Lindahl H. Epidemiology of periprosthetic femur fracture around a total hip arthroplasty. Injury. 2007;38:651-654.

19. Mäkelä KT, Matilainen M, Pulkkinen P, Fenstad AM, Havelin L, Engesaeter L, Furnes O, Pedersen AB, Overgaard S, Kärrholm J, Malchau H, Garellick G, Ranstam J, Eskelinen A. Failure rate of cemented and uncemented total hip replacements: register study of combined Nordic database of four nations. BMJ. 2014;348: f7592.

20. Maloney WJ, Sychterz C, Bragdon C, McGovern T, Jasty M, Engh CA, Harris WH. The Otto Aufranc Award. Skeletal response to well fixed femoral components inserted with and without cement. Clin Orthop Relat Res. 1996;333:15-26.

21. McMinn DJW, Snell KIE, Daniel J, Treacy RBC, Pynsent PB, Riley RD. Mortality and implant revision rates of hip arthroplasty in patients with osteoarthritis: registry based cohort study. BMJ. 2012;344:e3319.

22. Mulier M, Jaecques SVN, Raaijmaakers M, Nijs J, Van der Perre G, Jonkers I. Early periprosthetic bone remodelling around cemented and uncemented custom-made femoral components and their uncemented acetabular cups. Arch Orthop Trauma Surg. 2011;131:941-948.

23. Overgaard S, Pedersen AB. Danish Hip Arthroplasty Registry Annual Rapport 2013. Available at: www.dhr.dk. Accessed September 2014

24. Pedersen AB, Mehnert F, Havelin LI, Furnes O, Herberts $\mathrm{P}$, Kärrholm J, Garellick G, Mäkela K, Eskelinen A, Overgaard S. Association between fixation technique and revision risk in total hip arthroplasty patients younger than 55 years of age. Results from the Nordic Arthroplasty Register Association. Osteoarthritis Cartilage. 2014;22:659-667.

25. Ranstam J, Kärrholm J, Pulkkinen P, Mäkelä K, Espehaug B, Pedersen AB, Mehnert F, Furnes O. Statistical analysis of arthroplasty data. I. Introduction and background. Acta Orthop. 2011;82:253-257.

26. Saleh KJ, Holtzman J, Gafni A, Saleh L, Davis A, Resig S, Gross AE. Reliability and intraoperative validity of preoperative assessment of standardized plain radiographs in predicting bone loss at revision hip surgery. J Bone Joint Surg Am. 2001;83: 1040-1046.

27. Troelsen A, Malchau E, Sillesen N, Malchau H. A review of current fixation use and registry outcomes in total hip arthroplasty: the uncemented paradox. Clin Orthop Relat Res. 2013; 471:2052-2059.

28. Weeden SH, Paprosky WG. Minimal 11-year follow-up of extensively porous-coated stems in femoral revision total hip arthroplasty. J Arthroplasty. 2002;17:134-137.

29. Willert HG, Ludwig J, Semlitsch M. Reaction of bone to methacrylate after hip arthroplasty: a long-term gross, light microscopic, and scanning electron microscopic study. J Bone Joint Surg Am. 1974;56:1368-1382. 